\title{
Cenários de disponibilidade hídrica para concessão de outorga: estudo de caso da Bacia Vertentes do Rio Grande, Estados de Minas Gerais e São Paulo, Brasil
}

\section{Heitor Soares Moreira, Kátia Soares Moreira*, Paulo Eduardo de Oliveira Sousa e Luiz Fernando Coutinho de Oliveira}

Universidade Federal de Lavras. Aquenta Sol, Lavras-MG, Brasil (CEP 37200-900). *E-mail: katiasoaresmoreira@hotmail.com.

Resumo. A Política Estadual de Recursos Hídricos visa a assegurar o controle, para usuários atuais e futuros, do uso da água e de sua utilização em quantidade, qualidade e regime satisfatórios. Como apenas parte das vazões mínimas de referência é outorgável, há a limitação do uso da água, principalmente nos períodos de maior disponibilidade hídrica, afetando diferentes usuários e suas atividades econômicas. Desta forma, há a necessidade de analisar a influência da sazonalidade das vazões nos critérios de outorga de uso da água. Neste contexto, o presente trabalho foi realizado com o objetivo de avaliar a regionalização de vazão sazonal, nas mais diversas vazões de referências, verificando a possibilidade do aumento na disponibilidade hídrica para os diferentes usuários da UPGRHGD2. Para a realização do trabalho, foram utilizados os softwares SisCah 1.0 e SisCorv 1.0, selecionadas as estações fluviométricas da região que apresentavam dados relativos ao período de 1967 a 2002, além da análise da base de dados de outorga do Instituto Mineiro de Gestão das Águas (IGAM). Os resultados obtidos permitiram concluir que o uso dos critérios baseados no comportamento hídrico sazonal propicia flexibilização nas vazões outorgáveis no período chuvoso do ano, para as vazões de referência $Q_{7,10}, Q_{90 \%}$ e $Q_{95 \%}$ e restrição no uso, no período de estiagem, para as vazões de referência $Q_{90 \%}$ e $Q_{95 \%}$.

Palavras-chave: Outorga sazonal; Gestão de recursos hídricos; Vazão de referência; Regionalização de vazão.

Abstract. Water availability scenarios for granting award: case study of rio grande vertentes, Minas Gerais and São Paulo States, Brazil. The State Water Resources Policy aims to ensure the control, for current and future users, of water use and its use in quantity, quality and satisfactory regime. As only part of the minimum reference flows are granted, there is a limitation of water use, especially in periods of greater water availability,
Recebido

$08 / 01 / 2020$

Aceito

$28 / 04 / 2020$

Publicado

$30 / 04 / 2020$

Acesso aberto

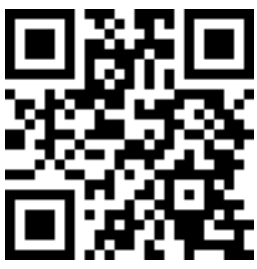

(1) 0000-0002-4546-8390 Heitor Soares Moreira

(1) 0000-0001-8724-3133

Kátia Soares Moreira

(D) 0000-0002-0297-6109

Paulo Eduardo de Oliveira Sousa

(D) 0000-0001-5260-3258

Luiz Fernando

Coutinho de Oliveira

ISSN 2359-1412/RBGAS-2020-0002/2020/7/15/24/341

Rev. Bras. Gest. Amb. Sustent.

http://revista.ecogestaobrasil.net 
affecting different users and their economic activities. Thus, it is necessary to analyze the influence of the seasonality of the flows in the criteria of granting water use. In this context, the present study was carried out with the objective of evaluating the regionalization of seasonal flow, in the most diverse reference flows, verifying the possibility of the increase in water availability for the different UPGRH-GD2 users. In order to carry out this study, the software SisCah 1.0 and SisCorv 1.0 were used, selecting the fluviometric stations of the region that presented data related to the period from 1967 to 2002, as well as the analysis of the granting database of the Minas Gerais Institute of Management Waters (IGAM). The results obtained allowed to conclude that the use of the criteria based on the seasonal water behavior facilitates flexibility in the flow rates in the rainy season of the year, for the reference flows $Q_{7,10}, Q_{90 \%}$ and $Q_{95 \%}$ and restriction on the use, during the dry season, for the reference flows $Q_{90 \%}$ and $Q_{95 \%}$.

Keywords: Water availability; Water resource management; Reference flow.

\section{Introdução}

A água é fundamental para a vida, estando distribuída amplamente no globo terrestre. Contudo, nem toda água está disponível ou é de fácil acesso para o uso humano. Outro fato preponderante é a distribuição da parcela de água superficial doce no planeta, existindo regiões privilegiadas e nas quais ela está presente em uma fração significativa. Essa distribuição natural da quantidade de água e a sazonalidade dos eventos pluviais são responsáveis por problemas de escassez hídrica, a qual é considerada um problema, quando analisada do ponto de vista econômico. Neste sentido, a água passa ser considerada insumo de produção e tratada como recurso hídrico.

Entre as consequências mais amplamente previstas e aceitas das mudanças climáticas globais está o aumento na frequência e na gravidade de uma variedade de eventos climáticos extremos. Tais eventos meteorológicos incluem fortes chuvas e inundações, ciclones, secas, ondas de calor, frio extremo e incêndios florestais, e cada um deles pode impactar a qualidade da água potável, afetando as bacias hidrográficas, os reservatórios de armazenamento, o desempenho de processos de tratamento de água ou a integridade dos sistemas de distribuição (Khan et al., 2015).

Segundo Zhou et al. (2015), devido às características de adaptação, às dinâmicas e aos multiobjetivos do sistema de recursos hídricos, gerenciar esses recursos de forma eficiente, equitativa e sustentável torna-se um desafio considerável.

A outorga tem como objetivo assegurar o controle quantitativo e qualitativo dos usos da água e o efetivo exercício dos direitos de acesso aos recursos hídricos. Esse controle é necessário para evitar conflitos entre os usuários desses recursos e para assegurar-lhes o efetivo direito de acesso à água.

As vazões mínimas de referência adotadas para fins de outorga, pelos órgãos gestores de recursos hídricos, influenciam diretamente o total disponível para outorga. Os critérios para análise dos pedidos de outorga utilizados pelos órgãos gestores se baseiam em diferentes vazões mínimas de referência, bem como em percentuais considerados outorgáveis (Silva et al., 2015). 
Neste sentido, o cálculo da vazão de referência contemplando a sazonalidade flexibiliza o uso dos recursos hídricos em determinados meses ou estações do ano. Essa flexibilização permite o aumento do uso desses recursos, evitando o conflito e que gestores públicos possam planejar o desenvolvimento econômico da região.

No presente estudo foi constatado que, na UPGRH-GD2, o procedimento adotado para a regularização do uso utilizado pelo Igam pode restringir, em até quatro vezes, o uso em determinados meses do ano, dependendo do trecho da hidrografia. Portanto, a avaliação do uso das vazões de referência sazonal para a concessão de outorga nesta Unidade é de suma importância para o aprimoramento do processo de gestão de seus recursos hídricos.

Com base neste contexto, o presente trabalho foi realizado com o objetivo de simular os diversos cenários de uso de recursos hídricos, com as mais diversas vazões de referência na base anual e sazonal, na Unidade de Planejamento e Gestão de Recursos Hídricos Vertentes do Rio Grande, UPGRH-GD2, no intuito de dar suporte às autoridades gestoras nas emissões da outorga de direito dos usos das águas.

\section{Material e métodos}

A Bacia Hidrográfica do Rio das Mortes integra a Bacia Hidrográfica do Rio Grande, que engloba territórios dos Estados de Minas Gerais e São Paulo, perfazendo 143.437,79 $\mathrm{km}^{2}$, dos quais 60,2\% estão em território mineiro e 39,8\%, em terras paulistas (IPT, 2008). A Bacia Hidrográfica do Rio Grande subdivide-se em 14 unidades de gestão de recursos hídricos, sendo seis em território paulista e oito em território mineiro.

Tabela 1. Relação das estações fluviométricas utilizadas no estudo de regionalização.

\begin{tabular}{|c|c|c|c|c|}
\hline Código & Nome & Rio & Município & $\begin{array}{c}\text { Área de drenagem } \\
\left(\mathrm{km}^{2}\right)\end{array}$ \\
\hline 61012000 & $\begin{array}{l}\text { Madre de Deus de } \\
\text { Minas }\end{array}$ & Grande & $\begin{array}{l}\text { Madre de Deus de } \\
\text { Minas }\end{array}$ & 2070 \\
\hline 61085000 & Campolide & Mortes & Antônio Carlos & 569 \\
\hline 61090000 & Barroso & Mortes & Barroso & 1040 \\
\hline 61100000 & Ibertioga & Elvas & Ibertioga & 186 \\
\hline 61105000 & Porto do Elvas & Elvas & Tiradentes & 828 \\
\hline 61107000 & Porto Tiradentes & Mortes & São João Del Rei & 2720 \\
\hline 61115000 & $\begin{array}{c}\text { Usina São João Del } \\
\text { Rei }\end{array}$ & Carandaí & $\begin{array}{l}\text { Coronel Xavier } \\
\text { Chaves }\end{array}$ & 643 \\
\hline 61122000 & Vila Rio das Mortes & $\begin{array}{l}\text { Mortes } \\
\text { pequeno }\end{array}$ & São João Del Rei & 272 \\
\hline 61145000 & Macaia & Grande & Bom sucesso & 15400 \\
\hline 61173000 & $\begin{array}{l}\text { Usina Couro do } \\
\text { Cervo }\end{array}$ & $\begin{array}{l}\text { Couro do } \\
\text { cervo }\end{array}$ & Lavras & 390 \\
\hline 61175000 & Usina Nepomuceno & Cervo & Nepomuceno & 1020 \\
\hline 61202000 & Santana do Jacaré & Jacaré & Santana do Jacaré & 1620 \\
\hline
\end{tabular}

A área selecionada para a elaboração do estudo de regionalização abrange a UPGRH-GD1, a UPGRH-GD2 e parte da UPGRH-GD3. Ressalta-se que as avaliações comparativas entre as vazões mínimas sazonais na base anual e mensal e os usos de recursos hídricos foram feitos restritamente à UPGRH-GD2. 


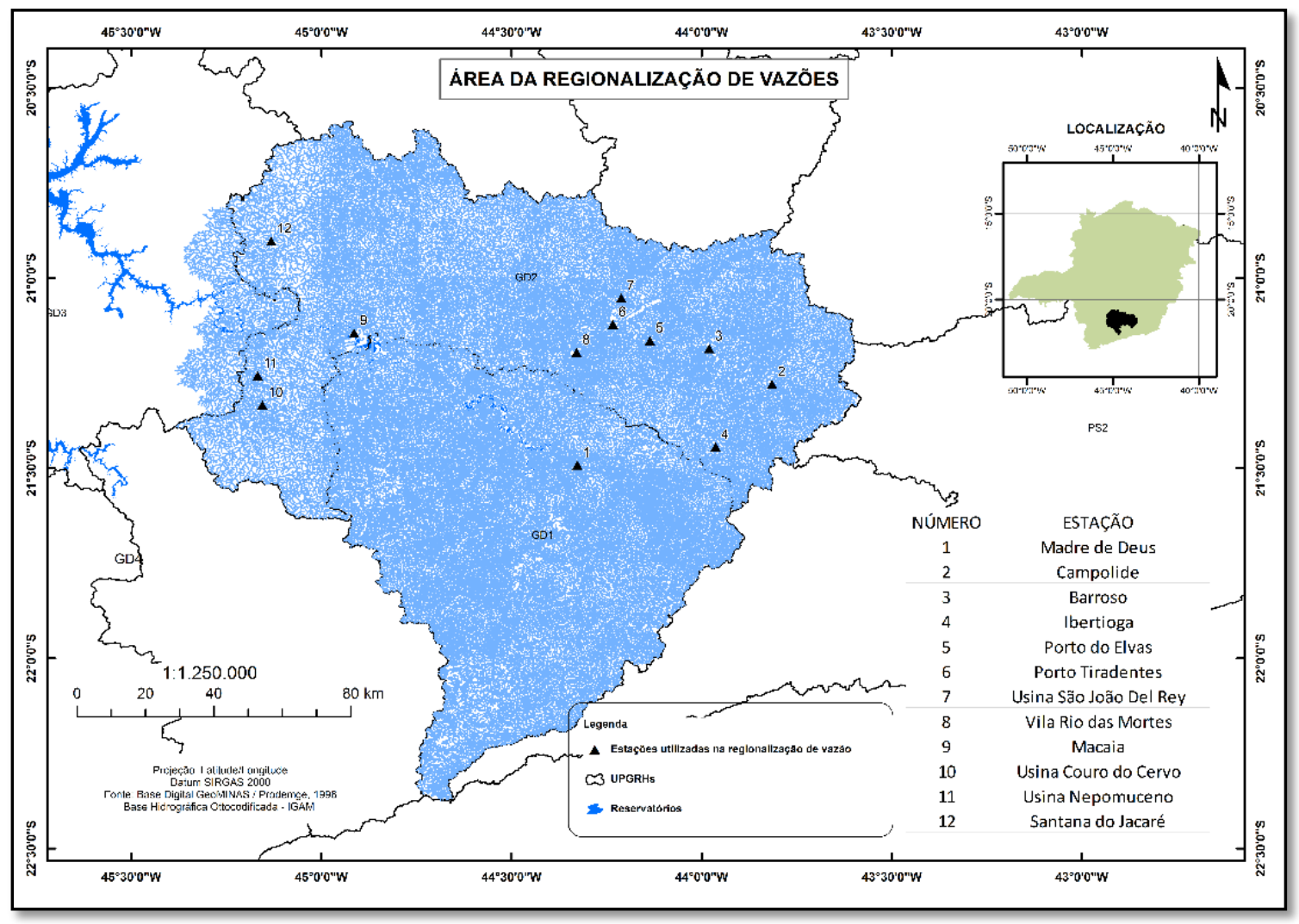

Figura 1. Área da regionalização de vazões com as estações fluviométricas e UPGRH.

No intuito de selecionar o maior número de estações possíveis, com, no mínimo, 35 anos de série histórica, foi selecionado o período base de 1967 a 2002, o período com dados em que se conseguiu o maior número de estações. Assim, foram identificadas, para o estudo de regionalização, 12 estações fluviométricas (Tabela 1 e Figura1).

Para a identificação das áreas homogêneas, foi gerado o gráfico boxplot das estações a partir das vazões específicas, avaliados o coeficiente de determinação, o coeficiente de determinação ajustado e o Teste $F$, e verificada a similaridade das características geográficas das regiões.

Para as avaliações estatísticas utilizaram-se os softwares Minitab, para gerar os gráficos boxplot e análise de regressão; Análises de Dados, do Excel 2016 para análise de regressão e teste de F, e SisCorV 1.0, para análise de regressão e testes F e P.

A partir das estimativas das vazões mínimas de referência foram comparadas as vazões do período mensal e a do período anual. Nessa comparação foi verificada a diferença relativa da disponibilidade hídrica na vazão outorgável, considerando a adoção das vazões mínimas de referência do período mensal com o período anual, conforme a Equação 1.

$$
D p=\left(\frac{\text { Qsazonal }- \text { Qanual }}{\text { Qanual }}\right) \cdot 100
$$

Em que:

Dp - diferença relativa percentual da disponibilidade hídrica;

Qsazonal - vazão estimada em base sazonal $\left(\mathrm{m}^{3} \mathrm{~s}^{-1}\right)$;

Qanual - vazão estimada em base anual $\left(\mathrm{m}^{3} \mathrm{~s}^{-1}\right)$. 
Para a realização do estudo de regionalização de vazões foram utilizados os Sistemas Computacionais para Regionalização de Vazões SisCoRV 1.0 e SisCAH 1.0. O método adotado para o estudo de regionalização foi o método tradicional, por ser aplicável às vazões mínimas, bem como à curva de permanência.

\section{Resultados e discussão}

Na Tabela 2 apresenta-se as diferenças percentuais das vazões sazonais em relação à anual correspondente às estações fluviométricas utilizadas no estudo. Verifica-se, pela análise dos valores da referida tabela, que houve flexibilidade do uso das vazões com a adoção dos períodos sazonais. $\mathrm{Na}$ análise da $\mathrm{Q}_{7,10}$ verifica-se que os meses chuvosos apresentaram flexibilidade média mínima, em novembro, de 41,25\% e máxima, em fevereiro, de 142,57\%. Não houve flexibilização significativa das vazões nos meses secos, uma vez que, em poucos casos, as ocorrências de $Q_{7}$ anual ocorreram fora deste período. Desse modo, a $\mathrm{Q}_{7,10} \mathrm{em}$ base anual tem valor próximo aos correspondentes aos valores de $\mathrm{Q}_{7,10}$ dos meses secos. Contudo, o mês mais seco, setembro, teve incremento de 10,94\% na vazão de referência na base mensal.

Tabela 2. Diferença relativa percentual da disponibilidade hídrica.

\begin{tabular}{l|c|c|c|c|c|c|c|c|c|c|c|c}
\hline Estações & Jan & Fev & Mar & Abr & Maio & Jun & Jul & Ago & Set & Out & Nov & Dez \\
\hline 61085000 & 149,72 & 121,36 & 131,94 & 98,36 & 73,02 & 62,80 & 46,78 & 25,98 & 25,08 & 16,81 & 62,28 & 139,55 \\
61090000 & 94,91 & 90,33 & 87,02 & 65,79 & 39,68 & 26,85 & 19,09 & 8,05 & 2,56 & 15,37 & 41,38 & 73,56 \\
61100000 & 102,66 & 65,09 & 83,93 & 59,65 & 44,97 & 31,79 & 25,90 & 13,99 & 5,66 & 14,45 & 32,95 & 98,15 \\
61105000 & 74,03 & 76,47 & 77,82 & 52,31 & 31,35 & 24,07 & 19,81 & 7,40 & 3,53 & 8,32 & 19,13 & 76,56 \\
61107000 & 132,68 & 123,98 & 128,68 & 91,40 & 67,02 & 47,00 & 33,83 & 15,27 & 8,22 & 12,84 & 49,54 & 121,54 \\
61115000 & 213,90 & 152,00 & 174,88 & 119,46 & 89,07 & 71,41 & 43,85 & 19,02 & 11,71 & 29,17 & 96,93 & 206,39 \\
61122000 & 170,80 & 166,38 & 146,21 & 108,74 & 81,17 & 53,12 & 38,42 & 17,10 & 14,41 & 10,37 & 37,94 & 130,93 \\
61145000 & 116,08 & 113,95 & 82,93 & 57,94 & 46,19 & 27,59 & 31,83 & 9,95 & 6,03 & 14,06 & 31,74 & 84,07 \\
61173000 & 74,00 & 125,85 & 114,65 & 86,22 & 68,89 & 49,85 & 44,69 & 26,19 & 12,71 & 10,03 & 8,37 & 33,30 \\
61175000 & 90,77 & 124,02 & 126,72 & 92,77 & 62,47 & 45,00 & 32,08 & 14,07 & 6,96 & 6,24 & 10,03 & 43,80 \\
61202000 & 316,09 & 393,66 & 326,70 & 224,33 & 133,91 & 89,27 & 81,36 & 43,46 & 26,70 & 47,93 & 73,35 & 191,42 \\
61012000 & 146,42 & 157,72 & 173,35 & 117,68 & 73,11 & 49,39 & 40,53 & 18,64 & 7,73 & 11,07 & 31,33 & 90,32 \\
\hline Média & 140,17 & 142,57 & 137,90 & 97,89 & 67,57 & 48,18 & 38,18 & 18,26 & 10,94 & 16,39 & 41,25 & 107,47 \\
\hline
\end{tabular}

A Figura 2 apresenta a comparação das vazões sazonal $Q_{7,10}$, com a vazão $Q_{7,10}$ calculada na base anual. Pode-se constatar que no mês de fevereiro houve uma diferença entre as $Q_{7,10}$ de aproximadamente $393 \%$. Em outras palavras, em um sistema de gestão de recursos hídricos em que se adota a vazão sazonal em detrimento a vazão anual, haveria uma disponibilidade hídrica para se outorgar, no referido mês, de aproximadamente $393 \%$ a mais. No período chuvoso, que na área de estudo, ocorre entre os meses de outubro a março, tem-se um incremento médio de vazão a ser outorgada de aproximadamente $225 \%$. Essa disponibilidade propicia aos setores industriais, mineração e de irrigação planejar suas produções e a desenvolver-se economicamente, sendo possível, nessas ocasiões, haver uma produção maior no período chuvoso e/ou o armazenamento do recurso hídrico para utilização no período de estiagem. 


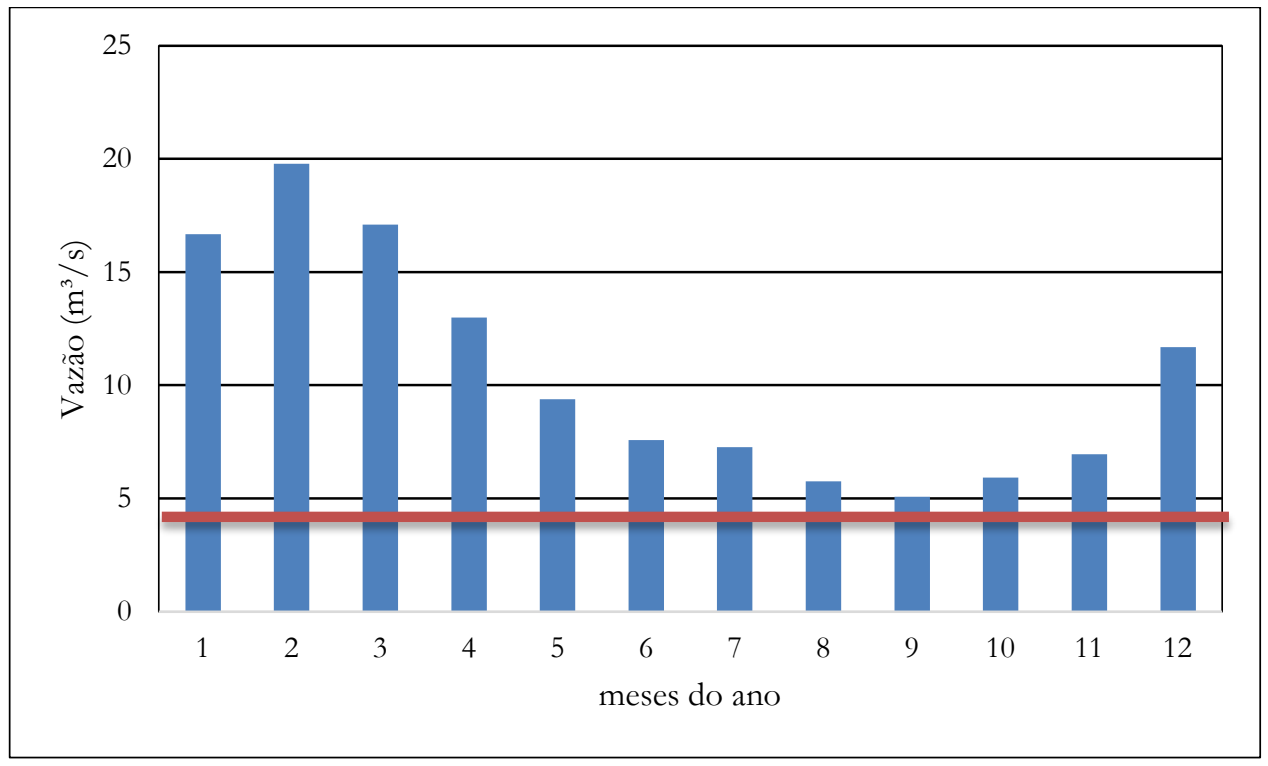

Figura 2. Comparação entre as vazões $Q_{7,10}$ sazonal e $Q_{7,10}$ anual na estação 61202000 .

Nas Tabelas 3 e 4 estão apresentadas as diferenças percentuais das vazões sazonais em relação à vazão anual correspondente às estações fluviométricas utilizadas no estudo. Verifica-se, pela análise dos valores apresentados na referida tabela, que houve flexibilidade, no período chuvoso, do uso das vazões com a adoção dos períodos sazonais. $\mathrm{Na}$ análise da $\mathrm{Q}_{90 \%}$ e $\mathrm{Q}_{95 \%}$ verifica-se que os meses chuvosos apresentaram flexibilidade média mínima, em novembro, de 5,18\% e máxima, em janeiro, de $84,25 \%$ para a $Q_{90 \%} \mathrm{e}$ mínima de 5,97\%, em junho, e máxima, em janeiro, de $87,20 \%$ para a vazão de referência $\mathrm{Q}_{95 \%}$. Nos meses mais secos, a vazão de referência na base sazonal restringe em até $20,6 \%$ a disponibilidade hídrica para outorga, quando se compara com o cálculo na base anual.

O fato da vazão $Q_{90 \%}$ e $Q_{95 \%}$, calculada na base sazonal, serem menores do que os valores anuais, restringe o uso no período de julho a outubro. Contudo, como se trata do período em que as vazões são as menores no ano hidrológico e consequentemente o período onde se tem a maior disputa pela quantidade de recursos hídricos, esse fato pode ser encarado como um fator de segurança para os usuários outorgados. Em outras palavras, àqueles usuários que obtiverem sua autorização de uso terá uma segurança maior quanto à disponibilidade hídrica na calha do curso hídrico.

Tabela 3. Diferença relativa percentual da disponibilidade hídrica.

\begin{tabular}{c|c|c|c|c|c|c|c|c|c|c|c|c}
\hline Estações & Jan & Fev & Mar & Abr & Maio & Jun & Jul & Ago & Set & Out & Nov & Dez \\
\hline 61085000 & 75,07 & 61,00 & 56,32 & 34,22 & 9,42 & $-1,37$ & $-11,21$ & $-26,64$ & $-20,38$ & $-15,38$ & 4,92 & 57,32 \\
61090000 & 62,44 & 54,13 & 47,57 & 32,27 & 9,84 & 0,57 & $-6,30$ & $-15,23$ & $-14,69$ & $-8,29$ & 17,29 & 50,16 \\
61100000 & 68,75 & 45,96 & 37,43 & 23,62 & 4,00 & $-5,66$ & $-11,32$ & $-15,93$ & $-13,21$ & $-12,45$ & 10,82 & 50,24 \\
61105000 & 68,51 & 59,51 & 51,93 & 22,65 & 7,46 & $-1,66$ & $-10,77$ & $-16,85$ & $-19,89$ & $-13,81$ & 6,08 & 51,24 \\
61107000 & 88,73 & 74,86 & 69,75 & 40,66 & 18,69 & 5,25 & $-2,70$ & $-16,18$ & $-21,97$ & $-13,88$ & $-0,03$ & 74,47 \\
61115000 & 108,47 & 92,24 & 76,53 & 32,64 & 14,13 & $-4,13$ & $-24,57$ & $-41,67$ & $-32,54$ & $-13,26$ & 29,01 & 96,30 \\
61122000 & 87,68 & 91,20 & 86,74 & 54,84 & 24,75 & 5,57 & $-5,57$ & $-22,29$ & $-20,82$ & $-22,29$ & 5,57 & 56,72 \\
61145000 & 79,04 & 48,48 & 50,70 & 19,55 & 3,12 & $-6,75$ & $-6,89$ & $-20,39$ & $-24,61$ & $-12,08$ & 6,96 & 49,44 \\
61173000 & 47,68 & 62,79 & 73,14 & 46,09 & 32,57 & 17,18 & 7,66 & $-6,13$ & $-14,93$ & $-17,86$ & $-14,93$ & 0,39 \\
61175000 & 81,21 & 83,68 & 104,12 & 60,02 & 42,37 & 15,81 & 6,14 & $-7,99$ & $-8,78$ & $-2,98$ & 3,04 & 29,54 \\
61202000 & 127,17 & 152,90 & 136,57 & 63,47 & 26,28 & 2,90 & $-3,45$ & $-24,83$ & $-33,96$ & $-19,49$ & $-0,78$ & 73,94 \\
61012000 & 116,21 & 105,37 & 113,17 & 60,49 & 23,41 & 5,85 & $-5,85$ & $-17,56$ & $-21,46$ & $-13,66$ & $-5,85$ & 50,73 \\
\hline Média & 84,25 & 77,68 & 75,33 & 40,88 & 18,00 & 2,80 & $-6,24$ & $-19,31$ & $-20,60$ & $-13,79$ & 5,18 & 53,37 \\
\hline
\end{tabular}


Tabela 4. Diferença relativa percentual da disponibilidade hídrica.

\begin{tabular}{l|c|c|c|c|c|c|c|c|c|c|c|c}
\hline Estações & Jan & Fev & Mar & Abr & Maio & Jun & Jul & Ago & Set & Out & Nov & Dez \\
\hline 61085000 & 76,47 & 59,07 & 64,73 & 32,35 & 9,36 & 6,62 & $-10,78$ & $-20,34$ & $-21,08$ & $-26,72$ & 13,83 & 58,90 \\
61090000 & 59,85 & 54,73 & 43,45 & 31,43 & 5,43 & 1,55 & $-2,71$ & $-12,92$ & $-14,20$ & $-7,62$ & 14,40 & 46,63 \\
61100000 & 70,43 & 48,38 & 35,76 & 17,39 & $-4,79$ & $-2,17$ & $-15,65$ & $-24,37$ & $-14,35$ & $-4,35$ & 5,53 & 56,09 \\
61105000 & 73,97 & 59,94 & 51,16 & 25,64 & 5,13 & 0,00 & $-7,69$ & $-10,58$ & $-15,06$ & $-10,51$ & 10,26 & 49,36 \\
61107000 & 79,24 & 71,09 & 69,26 & 43,26 & 21,74 & 12,83 & $-7,50$ & $-17,93$ & $-21,41$ & $-11,96$ & 31,09 & 67,93 \\
61115000 & 159,26 & 142,56 & 96,88 & 44,14 & $-2,34$ & 3,91 & $-10,94$ & $-29,69$ & $-27,34$ & $-14,06$ & 75,78 & 155,29 \\
61122000 & 85,40 & 77,19 & 91,64 & 48,28 & 19,36 & $-5,84$ & $-9,81$ & $-24,40$ & $-20,42$ & $-26,39$ & 0,80 & 43,24 \\
61145000 & 78,57 & 45,94 & 37,58 & 17,69 & 2,90 & $-7,81$ & $-10,88$ & $-20,78$ & $-23,70$ & $-10,06$ & 10,80 & 48,25 \\
61173000 & 54,20 & 56,94 & 62,62 & 18,02 & $-7,42$ & 20,32 & $-20,24$ & $-23,41$ & $-15,16$ & $-12,87$ & $-10,24$ & 10,99 \\
61175000 & 86,84 & 72,93 & 82,13 & 45,79 & 24,96 & 20,31 & $-12,23$ & $-21,05$ & $-15,13$ & 6,50 & 13,28 & 39,11 \\
61202000 & 104,84 & 156,55 & 149,60 & 58,24 & 23,48 & 9,34 & 0,00 & $-25,75$ & $-39,04$ & $-20,62$ & 6,28 & 56,55 \\
61012000 & 117,35 & 79,32 & 99,43 & 56,75 & 32,23 & 12,56 & $-3,12$ & $-18,80$ & $-21,04$ & $-14,32$ & $-3,12$ & 48,41 \\
\hline Média & 87,20 & 77,05 & 73,69 & 36,58 & 10,84 & 5,97 & $-9,30$ & $-20,83$ & $-20,66$ & $-12,75$ & 14,06 & 56,73 \\
\hline
\end{tabular}

As Figuras 3 e 4 ilustram as vazões sazonal e anual na estação 61202000. 0 comportamento das vazões observadas nesta estação se replica em todas as demais estações utilizadas neste trabalho.

As vazões da curva de permanência, $Q_{90 \%}$ e $Q_{95 \%}$, se apresentam como uma vazão de referência mais apropriada para gestão de recursos hídricos por retratar de maneira mais precisa a sazonalidade em uma bacia hidrográfica, pois propiciam uma maior flexibilidade no período chuvoso e uma restrição no período de estiagem.

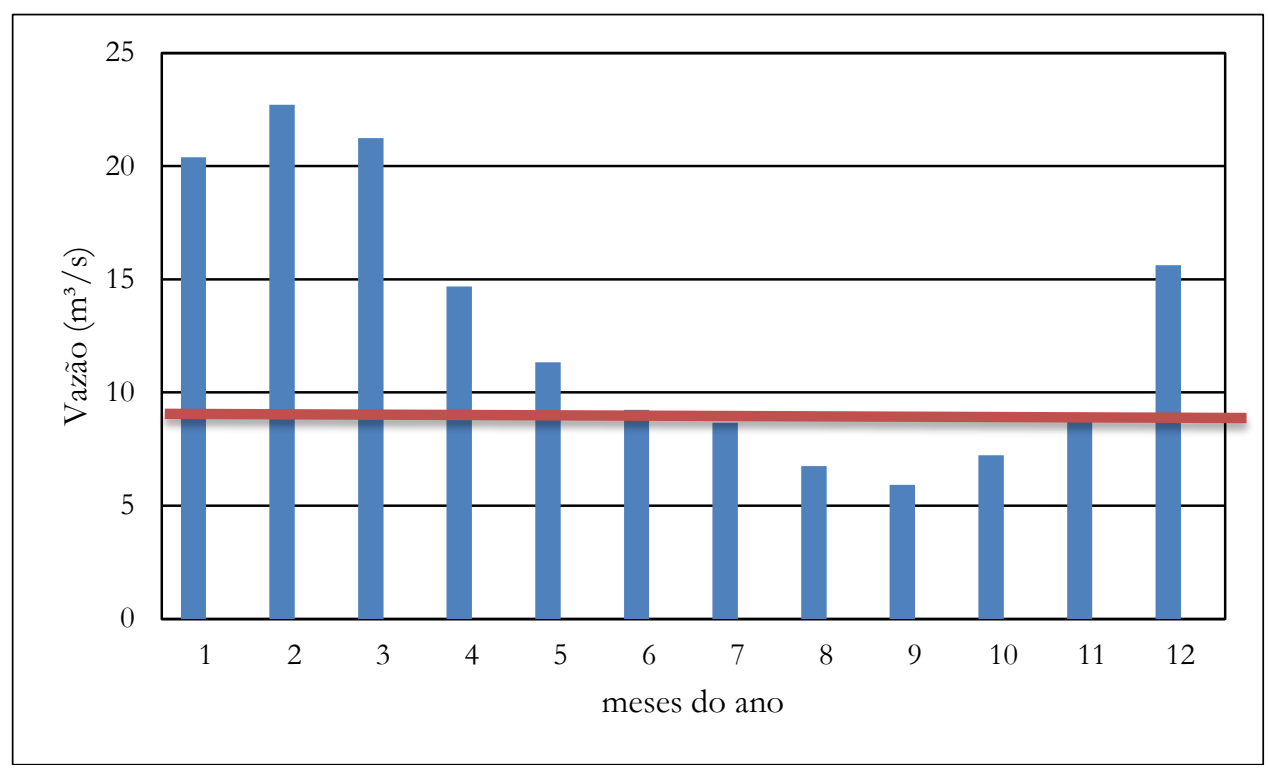

Figura 3. Comparação entre as vazões $Q_{90}$ sazonal e $Q_{90}$ anual na estação 61202000. 


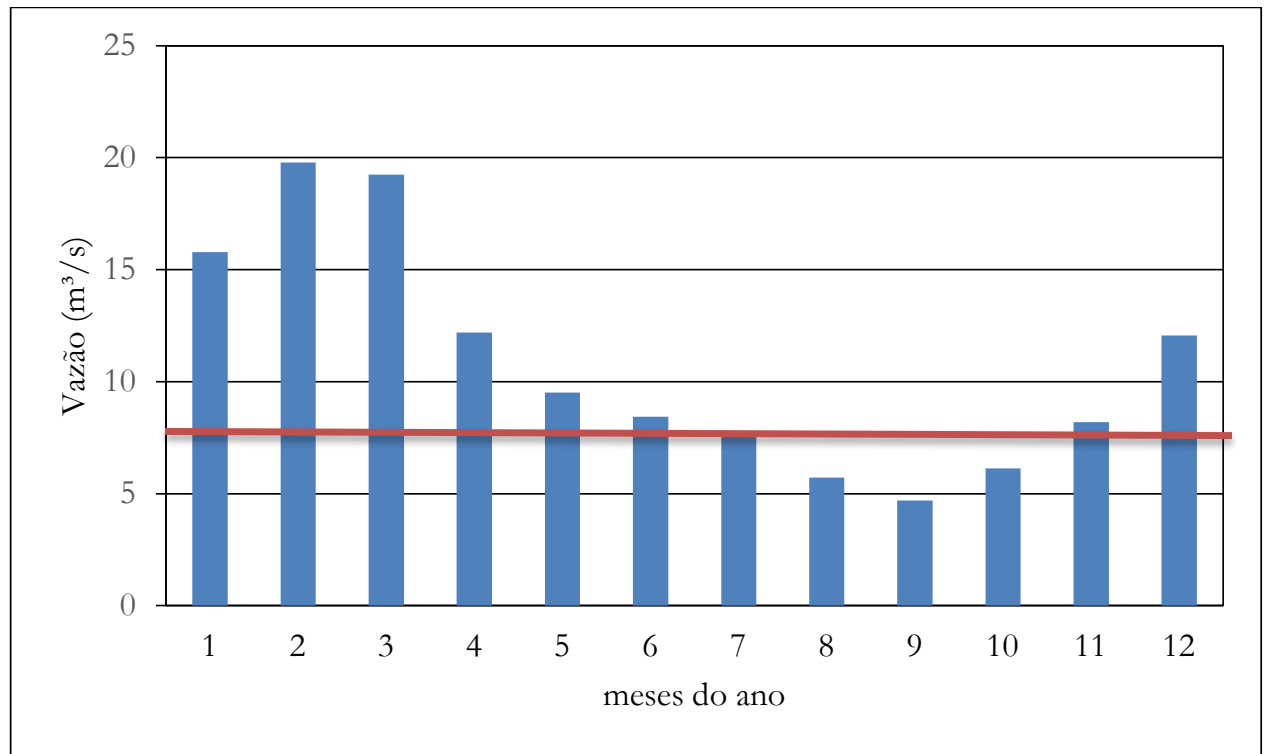

Figura 4. Comparação entre as vazões $Q_{95}$ sazonal e $Q_{95}$ anual na estação 61202000.

A diferença relativa percentual da disponibilidade hídrica deparada nas estações fluviométricas, pode ser replicada para um estudo de regionalização. As Tabelas 5 a 7 apresenta as equações de regionalização, na base sazonal e anual, nas mais diversas vazões de referência, $Q_{7,10}, Q_{90 \%}$ e $Q_{95 \%}$, na UPGRH GD2.

Tabela 5. Equações da regionalização da vazão de referência mínima, $Q_{7,10}$.

\begin{tabular}{|l|l|c|}
\hline Período & \multicolumn{1}{|c|}{ Equação } & $\mathbf{R}^{\mathbf{2}}$ \\
\hline Anual & $\mathrm{Q}_{7,10}=0,002882351418 \mathrm{~A}^{1,07233219}$ & 0,9513 \\
\hline Jan & $\mathrm{Q}_{7,10}=0,00584890192064906 \mathrm{~A}^{1,09206719931787}$ & 0,9903 \\
\hline Fev & $\mathrm{Q}_{7,10}=0,00501951920122214 \mathrm{~A}^{1,11437105372683}$ & 0,9851 \\
\hline Mar & $\mathrm{Q}_{7,10}=0,00625329243135336 \mathrm{~A}^{1,08070908233456}$ & 0,9842 \\
\hline Abr & $\mathrm{Q}_{7,10}=0,0054712989439529 \mathrm{~A}^{1,07457684176439}$ & 0,9838 \\
\hline Maio & $\mathrm{Q}_{7,10}=0,0048439401531696 \mathrm{~A}^{1,06927568506015}$ & 0,9818 \\
\hline Jun & $\mathrm{Q}_{7,10}=0,00450914184806337 \mathrm{~A}^{1,06164310819098}$ & 0,9776 \\
\hline Jul & $\mathrm{Q}_{7,10}=0,00370670199505295 \mathrm{~A}^{1,08051250319006}$ & 0,9741 \\
\hline Ago & $\mathrm{Q}_{7,10}=0,00349668130985493 \mathrm{~A}^{1,06691720587567}$ & 0,9662 \\
\hline Set & $\mathrm{Q}_{7,10}=0,00321524588051199 \mathrm{~A}^{1,06919810972178}$ & 0,9645 \\
\hline Out & $\mathrm{Q}_{7,10}=0,00312786037892518 \mathrm{~A}^{1,08129609589579}$ & 0,9727 \\
\hline Nov & $\mathrm{Q}_{7,10}=0,00357838940386901 \mathrm{~A}^{1,08632419267012}$ & 0,9767 \\
\hline Dez & $\mathrm{Q}_{7,10}=0,00549279434980362 \mathrm{~A}^{1,07760836397886}$ & 0,9767 \\
\hline
\end{tabular}


Tabela 6. Equações da regionalização da vazão de referência mínima, $Q_{90 \%}$.

\begin{tabular}{|l|l|c|}
\hline Período & \multicolumn{1}{|c|}{ Equação } & $\mathbf{R}^{\mathbf{2}}$ \\
\hline Anual & $Q_{90 \%}=0,00497769826617877 \mathrm{~A}^{1,06018551091885}$ & 0,9809 \\
\hline Jan & $Q_{90 \%}=0,00732348023890002 \mathrm{~A}^{1,09177180115659}$ & 0,9870 \\
\hline Fev & $\mathrm{Q}_{90 \%}=0,00827045903652115 \mathrm{~A}^{1,06815705775594}$ & 0,9871 \\
\hline Mar & $\mathrm{Q}_{90 \%}=0,00764579045472567 \mathrm{~A}^{1,07751479765357}$ & 0,9845 \\
\hline Abr & $\mathrm{Q}_{90 \%}=0,00743580659260564 \mathrm{~A}^{1,050850533288233}$ & 0,9832 \\
\hline Maio & $\mathrm{Q}_{9 \%}=0,00637732742618776 \mathrm{~A}^{1,04757164397481}$ & 0,9839 \\
\hline Jun & $\mathrm{Q}_{90 \%}=0,00551602678121465 \mathrm{~A}^{1,04893391044661}$ & 0,9794 \\
\hline Jul & $\mathrm{Q}_{90 \%}=0,00438808999893264 \mathrm{~A}^{1,06857894143035}$ & 0,9763 \\
\hline Ago & $\mathrm{Q}_{9 \%}=0,00396301196458446 \mathrm{~A}^{1,0611721269524}$ & 0,9630 \\
\hline Set & $\mathrm{Q}_{90 \%}=0,00470492897554516 \mathrm{~A}^{1,03431138755518}$ & 0,9648 \\
\hline Out & $\mathrm{Q}_{90 \%}=0,00393451804707189 \mathrm{~A}^{1,07255198853012}$ & 0,9779 \\
\hline Nov & $\mathrm{Q}_{90 \%}=0,00543544816654206 \mathrm{~A}^{1,05402137331505}$ & 0,9782 \\
\hline Dez & $\mathrm{Q}_{90 \%}=0,00633307731190544 \mathrm{~A}^{1,08554449929693}$ & 0,9782 \\
\hline
\end{tabular}

Tabela 7. Equações da regionalização da vazão de referência mínima, $Q_{95 \%}$.

\begin{tabular}{|l|l|c|}
\hline Período & \multicolumn{1}{|c|}{ Equação } & $\mathbf{R}^{\mathbf{2}}$ \\
\hline Anual & $\mathrm{Q}_{95 \%}=0,00387751976742885 \mathrm{~A}^{1,07203324559747}$ & 0,9713 \\
\hline Jan & $\mathrm{Q}_{95 \%}=0,0064810264689855 \mathrm{~A}^{1,08706940452937}$ & 0,9835 \\
\hline Fev & $Q_{95 \%}=0,00685427400762271 \mathrm{~A}^{1,06993667335452}$ & 0,9898 \\
\hline Mar & $\mathrm{Q}_{95 \%}=0,00677544750745082 \mathrm{~A}^{1,06895714488506}$ & 0,9803 \\
\hline Abr & $\mathrm{Q}_{95 \%}=0,00501924218500127 \mathrm{~A}^{1,07901936131262}$ & 0,9765 \\
\hline Maio & $Q_{95 \%}=0,00344553327310549 \mathrm{~A}^{1,10314292879916}$ & 0,9672 \\
\hline Jun & $Q_{95 \%}=0,00423355022684571 \mathrm{~A}^{1,06718223964965}$ & 0,9690 \\
\hline Jul & $Q_{95 \%}=0,00301799335595929 \mathrm{~A}^{1,09395747483755}$ & 0,9709 \\
\hline Ago & $Q_{95 \%}=0,00276872855651406 \mathrm{~A}^{1,08669049430556}$ & 0,9573 \\
\hline Set & $Q_{95 \%}=0,00368985048357063 \mathrm{~A}^{1,0450720025532}$ & 0,9479 \\
\hline Out & $Q_{95 \%}=0,00306422900762033 \mathrm{~A}^{1,08565480564081}$ & 0,9653 \\
\hline Nov & $\mathrm{Q}_{95 \%}=0,00391143807467177 \mathrm{~A}^{1,08776386864402}$ & 0,9805 \\
\hline Dez & $\mathrm{Q}_{95 \%}=0,00569288597421025 \mathrm{~A}^{1,07892139050493}$ & 0,9778 \\
\hline
\end{tabular}

\section{Conclusões}

Em todos os cenários estudados, $\mathrm{Q}_{7,10}, \mathrm{Q}_{90}$ e $\mathrm{Q}_{95}$ identificou-se, na UPGRH GD2, uma disponibilidade hídrica maior para se outorgar no período chuvoso. A adoção de outorga sazonal propicia o uso mais eficiente da água, viabilizando, por exemplo, o aumento da área com agricultura irrigada, desassoreamento e/ou descomissionamento de reservatórios com menor impacto sobre a qualidade das águas e aumento na produção industrial.

O uso de critérios baseados em vazões mensais baixas, em vez da anual baixa, tem grande potencial para aumentar o uso de recursos hídricos. 0 uso de $Q_{7,10}$ mensais, que substitui o $Q_{7,10}$ anual, implica aumentos no uso potencial de recursos hídricos que variam de valores de cerca de 10\% (meses com menor disponibilidade de água) a valores superiores a 393\% (meses com maior disponibilidade de água). Entretanto, não houve diferença significativa da $Q_{7,10}$, nos meses secos em relação à base anual.

Os usos das vazões $Q_{90 \%}$ e $Q_{95 \%}$ mensais, que substituem o valor anual de $Q_{90 \%} \mathrm{e}$ $\mathrm{Q}_{95 \%}$, implicam em alterações no uso potencial de recursos hídricos, desde reduções de $33 \%$ (meses com menor disponibilidade de água) até aumentos superiores a 100\% (meses 
com maior disponibilidade). 0 fato de os valores mensais de $Q_{90 \%}$ e $Q_{95 \%}$ serem menores do que o valor anual de $Q_{90 \%}$ e $Q_{95 \%}$ não deve ser considerado como uma restrição à disponibilidade de uso da água, mas sim como um aumento na garantia ambiental e para suprir a demanda por recursos hídricos.

\section{Agradecimentos}

Os autores gostariam de expressar sinceros agradecimentos à Universidade Federal de Lavras (UFLA) e ao Instituo Mineiro de Gestão das Águas (IGAM) por fornecerem as condições de realização do presente estudo, assim como, todos as pessoas que de alguma forma contribuíram para a realização do mesmo.

\section{Referências}

IPT - Instituto de Pesquisas Tecnológicas. Diagnóstico da situação dos recursos hídricos na Bacia hidrográfica do Rio Grande. São Paulo: IPT, 2008.

Khan, S. J.; Deereb, D.; Leusch, F. D. L.; Humpage, A.; Jenkins, M.; Cunliffef, D. Extreme weather events: Should drinking water quality management systems adapt to changing risk profiles? Water Research, v. 85, p.124-136, 2015. https://doi.org/10.1016/ j.watres.2015.08.018

Silva, B. M. B.; Silva, D. D.; Moreira, M. C. Influência da sazonalidade das vazões nos critérios de outorga de uso da água: estudo de caso da bacia do Rio Paraopeba. Revista Ambiente \& Água, v. 10, n. 3, p. 623-634, 2015. https://doi.org/10.4136/ambi-agua.1587

Zhou, Y.; Guo, S.; Xua, C.-Y.; Liu , D.; Chen, L.; Ye, Y. Integrated optimal allocation model for complex adaptive system of water resources management (I): Methodologies. Journal of Hydrology, v. 531, p. 964-976, 2015. https://doi.org/10.1016/j.jhydrol.2015.10.007

Informação da Licença: Este é um artigo Open Access distribuído sob os termos da Licença Creative Commons Attribution, que permite uso irrestrito, distribuição e reprodução em qualquer meio, desde que a obra original seja devidamente citada. 